"We shall work to ensure that the co-operation among the scientists of so many countries which is developing to-day shall be a model for the integration of the world scientific effort after victory has been won."

\section{NEWTONIANISM AND SCHOLASTICISM}

IN his presidential address to the annual statutory meeting of the Royal Society of Edinburgh, under the title "Aristotle, Newton, Einstein", Prof. E. T. Whittaker compared the modern revolution in physics, by which the ideas of relativity and the quantum theory have displaced those of Newtonian mechanics, with the revolution in the seventeenth century when Newtonian mechanics triumphed at the expense of Aristotelian Scholasticism. His main thesis was that the Scholastic ideas which were destroyed by the movement of which the work of Newton marked the culmination, were a perverted form of the true philosophy of Aristotle, and that the modern outlook represents a return-or at least a tendency to return--to the true Aristotelian outlook. The work of Tycho and Kepler disproved and overthrew the existing Scholastic cosmology, but it contained nothing inherently irreconcilable with the Scholastic metaphysies and might conceivably have been absorbed into the philosophy of the Schoolmen by a peaceful and conservative revolution. Actually, however, what was essentially a new metaphysic was introduced. The basic postulate of the Newtonian mechanics, in which it differed sharply from Scholasticism, was the fundamental and independent status accorded to space and time. Persistence of bodies in time and their displacement in space became the concepts to which everything in the external world had to be reduced, and bodies moved in obedience to the forces which acted on them in space and time.

A partial return to the Aristotelian view that all change is a transition between a state which is potential and a state which is actual came with the doctrine of the conservation of energy, in which force is ignored and a change is represented by a transition between potential and other forms of energy ; and this tendency has more recently been emphasized by the quantum mechanics, in which the operator corresponding to classical potential energy is closely skin to the Aristotelian concept of potency. The introduction of 'minimum' principles, which culminated in 1915 when Hilbert introduced a 'world function' which determines all physical events in the universe by the condition that its integral taken over the whole of space-time is a minimum, marked another drift back to Aristotelianism, since such principles, like Aristotle's, are essentially teleological. General relativity, according to which gravitation represents a continual effort of the universe to straighten itself out, is so completely teleological that it would certainly have delighted the hearts of the Schoolmen. A free particle, in relativity theory, moves in a path determined solely by the curvatureproperties of space; it is, as the Aristotelians would say, in potency with regard to space.

The importance of quantum theory from this point of view is that it shows that there are events in the physical world which cannot be represented on the background of space and time. Space and time must accordingly be deposed from the dominant position which they held in Newtonianism. We must begin not with space and time but with events; and the atom, which has a potency of various states, is correlated to the states as potency is to act. It endures as the atom, while it takes different states in succession. Thus, the proton and neutron are now regarded as two 'states' of a single entity, often called a 'heavy particle'. In Aristotelian terms, the heavy particle would be 'matter' and its determinations as a neutron or proton would be its two possible 'forms'. Matter is correlated to form as potency to act.

The peculiarities of modern statistical theory also are conveniently expressible in Aristotelian language. An electron can freely interchange its recognizability with other electrons; it has no sameness of being, no proper identity, no separate history. Its selfhood is merged in an electronhood which it shares with all other electrons, and which is correlated with it as potency to act. This reopens the question which engaged so much attention in the Middle Ages, regarding the nature of universals, or general terms, which represent the common basis of a class of individual objects.

Prof. Whittaker considers that these tendencies of modern physics should lead to more intercourse and mutual understanding between men of science and philosophers; for of all types of philosophy, the Aristotelian-Scholastic is, in its principles, the most congenial to the scientific mind. It is in a sense true that correct, even if in some respects limited, knowledge regarding physics can be combined with any view whatever on the fundamental questions of being and reality, but the effect of such segregated thinking has been to make science a departmental affair, having no influence on life and thought except indirectly through its applications. At the present time there is a movement in scientific circles aiming at securing for science a greater influence on human affairs, and even calling for a refounding of civilization on a scientific basis; but its advocates do not always understand that, as a necessary condition for the possibility of such a reform, science must be reintegrated into a unity with philosophy and religion.

\section{ESKIMO CRANIOLOGY}

$T$ HE first part of a catalogue of human crania in the United States National Museum was issued in 1924. It gave measurements of four short series from parts of Alaska. Since then the Smithsonian Institution has sent eighteen anthropological expeditions to the country, and the United States National Museum now has 2,200 Eskimo skulls, many of which are accompanied by the rest of the skeleton. The latest part of the catalogue to be issued* provides individual measurements of the whole collection of skulls, including a number for which data had been published previously. Dr. Hrdlička, the doyen of American physical anthropologists, has thus made another substantial contribution to the long list of his achievements in collecting, describing and analysing the material of his science.

For each specimen nineteen absolute measurements and twelve measurements of shape (indices and angles)

* Proc. U.S. Nat. Mus., 91, 169-429 (1942). “Catalog of Human Crania in the United States National Museum Collections: Eskimo in General", by Aleš Hrdlicka. (Washington, D.C.: Gov. Printing Office.) 